\title{
Impact of Carob Pods Powder on the Physical and Sensory Properties of Ice Cream
}

\author{
Amira M. El-Kholy \\ Dairy Department, Faculty of Agriculture, Suez Canal University, Ismailia 41522, Egypt
}

Received: $17 / 6 / 2015$

\begin{abstract}
The effects of carob pod fruit powder as a partial replacement of ice cream mix SNF with levels of $8 \%, 16 \%$ and $24 \%$ on the physical and sensory properties of ice cream were evaluated. Specific gravity, weight per gallon, $\mathrm{pH}$ values, freezing point and some rheological parameters of the prepared ice cream mixes, also the overrun, melting resistance and sensory characteristics of the resultant ice cream were determined. Specific gravity, weight per gallon and freezing point of ice cream mixes increased by replacement of SNF with carob pods powder. Also, the addition of carob pods fruit caused significant $(\mathrm{p}<0.05)$ increase in apparent viscosity, plastic viscosity and consistency index along the aging period at $5 \pm 1^{\circ} \mathrm{C}$ for $24 \mathrm{hr}$. On contrary, overrun decreased significantly $(\mathrm{p}<0.05)$ as replacement of SNF increased. Moreover, the melting resistance (low melting ability) of carob ice cream showed a positive proportional $(\mathrm{p}<0.05)$ with replacement levels of carob pods powder. Partially replacement of ice cream SNF with carob pods powder up to the level of $24 \%$ can be considered as carob flavoured ice cream with good physical and sensory characteristics.
\end{abstract}

Keywords: Ice cream, carob pod, flavoured ice cream, Ceratonia seliqua

\section{INTRODUCTION}

Carob pod is the fruit of the carob tree (Ceratonia seliqua) and is a perennial leguminous tree, native to Mediterranean basin and southwest Asia (Santos et al., 2005). Carob pods characterized by a high content of carbohydrate (48-56\%) sucrose at more than 30\%, glucose, fructose and maltose, appreciable amount of protein (3\%), low levels of fat (0.6\%) (Priolo et al., $2000)$. In addition it contains about $18 \%$ cellulose and hemi cellulose. Ripe carob pods contain a large amount of condensed tannins (16-20\%) on dry weight basis (Karababa and Coskunder, 2013). It is also rich in fiber, vitamins $\left(\mathrm{A}, \mathrm{B}_{1}, \mathrm{~B}_{2}, \mathrm{D}\right)$ and minerals (iron, calcium, phosphorus and magnesium) as well as remarkably high potassium content (1.2\%-1.5\%) (Yasin and Ibrahim, 2004).

Carob is dried or roasted, and is mildly sweet. It is used (powdered, chip, or syrup form) as an ingredient in cakes and cookies, and is used as substitute for chocolate (Youssef et al., 2013 ${ }_{\mathrm{a}}$ ). So, carob is a natural sweetener with a flavour and appearance similar to chocolate which is used to improve aroma and taste in numerous food products. Crushed pods may be used to make beverage and syrup (Youssef et al., 2013 ). The economic importance of the carob (Ceratonia seliqua) comes from the industrial utilization of the locust bean gum (E410) obtained from its pods. This gum is employed in a wide range of products in the food industry; among the most important which is ice cream, baby foods (Santos et al., 2005).

Ice cream is one of the most consumed dairy products in the world (Hoyer, 1997). Ice cream and frozen desserts are mainly valued for their pleasant flavour, cooling effects and refreshing tastes (Barot Amit et al., 2014).

Therefore, the objective of this study was to determine the effects of carob pod fruit powder (due to its nutritional and healthy values) as partially replacing of ice cream mix SNF on the physical and sensory properties of ice cream.

\section{MATERIALS AND METHODS}

\section{Materials:}

Fresh buffalo's milk ( $9 \%$ SNF and $6 \%$ fat) was obtained from a private farm at Ismailia Governorate, and was separated to cream $(50 \%$ fat $)$ and skim milk which were used in ice cream making. Skim milk powder (Grade A- low heat - spray process-pasteurized) manufactured by West farm Foods (96\% total solids), U.S.A.. Gelatin powder was obtained from Adwic (El Nasr Pharmaceutical Chemicals). Sugar and a commercial carob pods (Ceratonia siliqua) were purchased from local market. The carob pods were grinded to very fine powder which had the values of 9.5 , $26.58,8.53$ and $16.8 \%$ for moisture, total sugar, ash and crude fiber, respectively.

\section{Methods:}

\section{Preparation of ice cream mixes}

Three replicates of ice cream mixes were prepared using carob pods powder to replace 8,16 and $24 \%$ of SNF in the prepared mixes (T2), (T3) and (T4) respectively. The control mix formula (T1) was standardized to contain $8 \%$ fat, $10 \%$ milk solids not fat, $15 \%$ sugar and $0.5 \%$ gelatin (Table 1 ). All mixes were heat treated at $80^{\circ} \mathrm{C}$ for $30 \mathrm{sec}$, then cooled to $4^{\circ} \mathrm{C}$ and aged at that temperature for $24 \mathrm{hr}$ prior to freezing. The mixtures $(2 \mathrm{Kg}$ mix for each treatment) were frozen in an ice cream freezing machine (Taylor-mate Model 156, Italy). The resultant ice cream was packaged in cups $(100 \mathrm{ml})$, and put in deep freezer at $-18^{\circ} \mathrm{C}$ for hardening according to Marshall and Arbuckle (1996) for $24 \mathrm{hr}$ before analysis and stored for 45 day.

\section{Methods of analysis:}

Moisture, crude fiber, total sugars and ash content of carob pod powder were determined according to A.O.A.C. (1990). Carob ice cream mix was analyzed for pH using Adwa pH meter (AD 1200 Professional Bench Meters, Adwa Instruments Kft, Hungary), Specific gravity (Winton, 1958), weight per gallon (Burke, 1947), freezing point (FAO Laboratory Manual, 1977), 
Table (1): Formulations of ice cream mixes using different levels of carob pods powder as SNF partial replacement.

\begin{tabular}{lcccc}
\hline \multirow{2}{*}{ Ingredient } & \multicolumn{3}{c}{$\begin{array}{c}\text { Formula No. } \\
\text { g/kg }\end{array}$} \\
\cline { 2 - 5 } & T1 & T2 & T3 & T4 \\
\hline Cream (50\% fat) & 160 & 160 & 160 & 160 \\
Buffalo's skim milk (9\% SNF) & 649.1 & 649.6 & 649.9 & 650.4 \\
Skim milk powder (96\% SNF) & 35.8 & 27.4 & 19.1 & 10.63 \\
Sugar & 150 & 138 & 126 & 114 \\
Gelatin & 5 & 5 & 5 & 5 \\
$\begin{array}{l}\text { Carob pods powder } \\
(90.5 \% \text { TS) }\end{array}$ & 0 & 20 & 40 & 60 \\
\hline
\end{tabular}

viscosity and some rheological parameters were carried out using a Brookfield Digital Rheometer model DVIII+ (Brookfield Engineering Laboratories, Inc., MA, USA), equipped with a $\mathrm{SC}_{4}-21$ spindle. Apparent viscosity was measured at shear rate $93 \mathrm{~S}^{-1}$. Measurements were made at temperature of $10^{\circ} \mathrm{C}$ in shear rate ranging from 23.3 to $232.5 \mathrm{~S}^{-1}$. All rheological properties were performed in duplicates.

The overrun of the resultant carob ice cream treatments were determined according to (Marshall and Arbuckle, 1996), melting resistant (Tharp et al., 1997), specific gravity (Winton, 1958) and weight per gallon (Burke, 1947).

\section{Sensory evaluation:}

The sensory evaluation for resultant ice cream treatments were carried out by 8 staff members of the Dairy Department, for flavour (45 points), body \&texture (30 points), and appearance \& colour (25 points).

\section{Statistical analysis:}

All obtained data were subjected to the statistical analysis and analysis of variance by the procedure of general linear model using CoStat (1998) under windows software version 6.311 and least significant difference (LSD) at $(\mathrm{p}<0.05)$.

\section{RESULTS AND DISCUSSION}

\section{Ice cream mix properties:}

Specific gravity and weight per gallon of ice cream mixes increased by replacement of SNF with carob pods powder (Table 2). The increase in specific gravity and weight per gallon were proportional to the amount of SNF replaced by carob pods powder. The same trend was found for $\mathrm{pH}$ values $(\mathrm{p}<0.05)$. The $\mathrm{pH}$ values for (T4) was decreased significantly $(\mathrm{p}<0.05)$ as compared to control ice cream. As it is seen from Table (2), the freezing point of ice cream mixes increased but not significantly $(\mathrm{p}>0.05)$ by using carob pods powder. This may be due to the lower lactose content in the treatments made with carob pods powder. Also, the freezing point increased with the increase of replacement percentage. This may be attributed to differences in nature and concentration of sweeteners in the different ice cream mixes (Salem and Massoud, 2003).

Table (2): Effect of replacement of SNF with carob pods powder on properties of ice cream mixes.

\begin{tabular}{lcccc}
\hline \multirow{2}{*}{ Properties } & \multicolumn{3}{c}{ Formula No.* } \\
\cline { 2 - 4 } & T1 & T2 & T3 & T4 \\
\hline Specific gravity $\left(\mathbf{g m} / \mathbf{c m}^{3}\right)$ & $1.1268^{\mathrm{d}}$ & $1.1271^{\mathrm{c}}$ & $1.1280^{\mathrm{b}}$ & $1.1283^{\mathrm{a}}$ \\
Weight/gallon $(\mathbf{K g})$ & $5.122^{\mathrm{c}}$ & $5.123^{\mathrm{c}}$ & $5.127^{\mathrm{b}}$ & $5.129^{\mathrm{a}}$ \\
pH value & $6.47^{\mathrm{a}}$ & $6.46^{\mathrm{a}}$ & $6.40^{\mathrm{b}}$ & $6.22^{\mathrm{c}}$ \\
Freezing point $\left({ }^{\circ} \mathbf{C}\right)$ & $-2.2^{\mathrm{a}}$ & $-2.16^{\mathrm{a}}$ & $-2.12^{\mathrm{a}}$ & $-2.10^{\mathrm{a}}$ \\
\hline
\end{tabular}

*T2, T3 and T4 different mixes containing 8,16 and $24 \%$ Carob pods powder respectively.

a, b, c \& d: means with the same letter among the treatments are not significantly different $(p<0.05)$.

The replacement of SNF with carob pods powder in ice cream mixes significantly $(p<0.05)$ affected the apparent and plastic viscosity as well as consistency indexes (Table 3). The addition of carob pods fruit caused significant $(p<0.05) \quad$ increase in apparent viscosity, plastic viscosity and consistency index along the aging period at $5 \pm 1^{\circ} \mathrm{C}$ for $24 \mathrm{hr}$. The apparent viscosity values of ice cream mixes significantly $(p<0.05)$ increased as carob pods powder ratios increased. This increment trend may be attributed to the 
increased levels of carob pods powder, due to its high content of fiber, which are characterized by its high water holding capacity (Vani and Zayas, 1995) The replacement of $24 \%$ of SNF (T4) by carob pods powder recorded the highest significant $(\mathrm{p}<0.05)$ increase in apparent viscosity, plastic viscosity and consistency indexes in fresh and through aging period.

Table (3): Rheological parameters of ice cream mixes prepared by replacement of solids not fat with carob pods powder at zero and $24 \mathrm{hrs}$ aging at $5 \pm 1^{\circ} \mathrm{C}$.

\begin{tabular}{|c|c|c|c|c|c|}
\hline \multirow{2}{*}{ Aging Time } & \multicolumn{4}{|c|}{ Formula No. $^{*}$} & \multirow{2}{*}{ Mean** } \\
\hline & T1 & $\mathbf{T}_{2}$ & $\mathbf{T}_{3}$ & $\mathbf{T}_{4}$ & \\
\hline \multicolumn{6}{|c|}{ Apparent Viscosity (m Pas) } \\
\hline 0 hour & 19.5 & 25.5 & 52.5 & 87 & $46.125^{\mathrm{b}}$ \\
\hline 24 hours & 119.5 & 164.5 & 306.5 & 836 & $356.625^{\mathrm{a}}$ \\
\hline Mean & $69.5^{\mathrm{D}}$ & $95^{\mathrm{C}}$ & $179.5^{\mathrm{B}}$ & $461.5^{\mathrm{A}}$ & \\
\hline \multicolumn{6}{|c|}{ Plastic viscosity (m Pas) } \\
\hline 0 hour & 11.1 & 15.9 & 26.4 & 40.2 & $23.4^{\mathrm{b}}$ \\
\hline 24 hours & 62.4 & 76.4 & 123.8 & 810 & $268.15^{\mathrm{a}}$ \\
\hline Mean & $36.75^{\mathrm{D}}$ & $46.15^{\mathrm{C}}$ & $75.1^{\mathrm{B}}$ & $425.1^{\mathrm{A}}$ & \\
\hline \multicolumn{6}{|c|}{ Consistency index (m Pas) } \\
\hline O hour & 16 & 17.6 & 30.3 & 100.8 & $41.175^{b}$ \\
\hline 24 hours & 96.5 & 143.5 & 303.4 & 825 & $342.10^{\mathrm{a}}$ \\
\hline Mean** & $56.25^{\mathrm{C}}$ & $80.55^{\mathrm{C}}$ & $166.85^{\mathrm{B}}$ & $462.9^{\mathrm{A}}$ & \\
\hline
\end{tabular}

"T2, T3 and T4 different mixes containing 8, 16 and $24 \%$ Carob pods powder respectively.

**a \& b and A, B, C \& D: means with the same letter among the treatments and aging period respectively are not significantly different $(\mathrm{p}<0.05)$.

\section{Ice cream properties:}

The results of Table (4) indicated that the replacement of SNF with carob pods powder increased significantly $(p<0.05)$ the specific gravity and weight per gallon of resultant ice cream. On the other hand the overrun decreased significantly $(\mathrm{p}<0.05)$ as replacement of SNF increased compared with control ice cream (T1). It was clearly indicated that as the specific gravity and weight per gallon decreased, the overrun increased. Mahran et al. (1984) stated that the specific gravity of ice cream is inversely proportional to changes occurring in the overrun. The decrease in the overrun which was observed by increasing the replacement ratio of SNF could be attributed to the obvious increase in mix viscosity.

The melting resistance (low melting ability) of carob ice cream showed a positive proportional $(p<0.05)$ with replacement levels of carob pods powder (Table 5). Hussein and Aumara (2006) stated that the differences in melting resistance are mainly due to the differences in the freezing points of the mixes. Herald et al. (2008), reported that increasing ice cream mix viscosity resulted in lower melting rate and improved product smoothness. The highest melting resistance of the samples with $24 \%$ replacement with carob pods powder (T4) could be attributed to the maximum viscosity for such mixes.

\section{Sensory evaluation:}

Data in Table (6) revealed that ice cream treatments prepared by the replacement of SNF with carob pods powder had the highest $(\mathrm{p}<0.05)$ scores for flavour without any adverse effect. Replacement up to $24 \%$ of SNF with carob pods powder resulted in significant $(\mathrm{p}<0.05)$ increase in scores of flavour and total acceptance scores as compared with control (T1). Also, the results indicated that body and texture of the experimental ice cream tended to be smooth without any defects. The addition of carob pods powder imparted an acceptable brown colour to the experimental ice cream. No significant $(\mathrm{p}<0.05)$ differences were found in scores for colour \& appearance and for body \& texture between different treatments. Ice cream with $24 \%$ (T4) carob pods powder replacement was the most preferred sample by the panelists. These results indicated that carob pods fruit could be successfully used for partially replacement of SNF in the preparation of ice cream. Based on the sensory results, carob pods fruit powder at replacing level of $24 \%$ of SNF is suitable for ice cream production without any flavour, body and texture or appearance defects.

\section{CONCLUSION}

Carob pods fruit was successfully used in the ice cream production. It can be concluded that carob pods powder can be incorporated into ice cream mix at a ratio of $24 \%$ of SNF. The obtained products can be considered as refreshing, pleasant flavoured ice cream with suitable and good physical and sensory characteristics. 
Table (4): Effect of replacement of solids not fat with carob pods powder on properties of resultant ice cream.

\begin{tabular}{lcccc}
\hline \multirow{2}{*}{ Properties } & \multicolumn{4}{c}{ Formula No. $^{\mathrm{k}}$} \\
\cline { 2 - 5 } Specific gravity $\left(\mathbf{g} / \mathbf{c m}^{3}\right)$ & $0.709^{\mathrm{d}}$ & $0.719^{\mathrm{c}}$ & $0.728^{\mathrm{b}}$ & $0.738^{\mathrm{a}}$ \\
Weight/gallon (Kg) & $3.223^{\mathrm{d}}$ & $3.268^{\mathrm{c}}$ & $3.309^{\mathrm{b}}$ & $3.354^{\mathrm{a}}$ \\
Overrun (\%) & $58.84^{\mathrm{a}}$ & $56.75^{\mathrm{b}}$ & $54.93^{\mathrm{b}}$ & $52.80^{\mathrm{c}}$ \\
\hline
\end{tabular}

"T2, T3 and T4 different mixes containing 8,16 and 24\% Carob pods powder respectively.

$\mathrm{a}, \mathrm{b}, \mathrm{c} \& \mathrm{~d}$ : means with the same letter among the treatments are not significantly different $(\mathrm{p}<0.05)$.

Table (5): Melting resistance (loss \%) of Carob ice cream prepared by replacement of solids not fat with carob pods powder within $60 \mathrm{~min}$.

\begin{tabular}{|c|c|c|c|c|c|}
\hline \multirow[t]{2}{*}{ Treatments ${ }^{*}$} & \multicolumn{4}{|c|}{ Melting resistance (loss \%) after } & \multirow{2}{*}{ Mean $^{* *}$} \\
\hline & $15 \mathrm{~min}$ & $30 \mathrm{~min}$ & $45 \mathrm{~min}$ & $60 \mathrm{~min}$ & \\
\hline T1 & 12.3 & 30 & 74.6 & 98.4 & $53.825^{\mathrm{A}}$ \\
\hline $\mathbf{T 2}$ & 11.2 & 27.2 & 71.3 & 96.2 & $51.465^{\mathrm{B}}$ \\
\hline T3 & 8.7 & 26.2 & 69.8 & 93.8 & $49.625^{\mathrm{C}}$ \\
\hline T4 & 8.4 & 23.2 & 63 & 91.2 & $46.45^{\mathrm{D}}$ \\
\hline Mean $^{* * *}$ & $10.15^{\mathrm{d}}$ & $26.65^{\mathrm{c}}$ & $69.67^{\mathrm{b}}$ & $94.9^{\mathrm{a}}$ & \\
\hline
\end{tabular}

${ }^{*} \mathrm{~T} 2, \mathrm{~T} 3$ and T4 different mixes containing 8,16 and $24 \%$ Carob pods powder respectively.

**a $a, b, c \& d$ and $A, B, C \& D$ : means with the same letter among the treatments and melting down duration respectively are not significantly different $(\mathrm{p}<0.05)$.

Table (6): Sensory evaluation of Carob ice cream prepared by replacement of solids not fat with carob pods powder during storage at $-18^{\circ} \mathrm{C}$.

\begin{tabular}{|c|c|c|c|}
\hline \multirow{2}{*}{ Treatments* } & \multicolumn{2}{|c|}{ Storage period (day) } & \multirow{2}{*}{ Mean** } \\
\hline & 1 & 45 & \\
\hline \multicolumn{4}{|c|}{ Flavour (45 points) } \\
\hline T1 & 42 & 41 & $41.5^{\mathrm{B}}$ \\
\hline $\mathbf{T} 2$ & 42 & 42 & $42^{\mathrm{B}}$ \\
\hline $\mathbf{T} 3$ & 43 & 42 & $42.5^{\mathrm{AB}}$ \\
\hline T 4 & 44 & 43 & $43.5^{\mathrm{A}}$ \\
\hline Mean** & $42.75^{\mathrm{a}}$ & $42^{\mathrm{a}}$ & \\
\hline \multicolumn{4}{|c|}{ Body \& Texture (30 points) } \\
\hline T1 & 28 & 28 & $28^{\mathrm{A}}$ \\
\hline T 2 & 28 & 28 & $28^{\mathrm{A}}$ \\
\hline $\mathbf{T} 3$ & 29 & 28 & $28.5^{\mathrm{A}}$ \\
\hline T 4 & 29 & 28 & $28.5^{\mathrm{A}}$ \\
\hline Mean** & $28.5^{\mathrm{a}}$ & $28^{\mathrm{a}}$ & \\
\hline \multicolumn{4}{|c|}{ Colour \& appearance (25 points) } \\
\hline T1 & 24.9 & 24 & $24.45^{\mathrm{A}}$ \\
\hline T 2 & 24.9 & 24 & $24.45^{\mathrm{A}}$ \\
\hline T 3 & 24.9 & 24 & $24.45^{\mathrm{A}}$ \\
\hline T 4 & 24.9 & 24 & $24.45^{\mathrm{A}}$ \\
\hline Mean** & $24.9^{\mathrm{a}}$ & $24^{\mathrm{b}}$ & \\
\hline \multicolumn{4}{|c|}{ Total acceptance (100 points) } \\
\hline T1 & 94.9 & 93 & $93.95^{\mathrm{A}}$ \\
\hline $\mathbf{T} 2$ & 94.9 & 94 & $94.45^{\mathrm{A}}$ \\
\hline $\mathbf{T} 3$ & 96.9 & 94 & $95.45^{\mathrm{A}}$ \\
\hline T 4 & 97.9 & 95 & $96.45^{\mathrm{A}}$ \\
\hline Mean** & $96.15^{\mathrm{a}}$ & $94^{\mathrm{b}}$ & \\
\hline
\end{tabular}

"T2, T3 and T4 different mixes containing 8,16 and 24\% Carob pods powder respectively.

${ }^{* *} \mathrm{a} \& \mathrm{~b}$ and A\& B means with the same letter among the treatments and storage period are not significantly different $(\mathrm{p}<0.05)$. 


\section{REFERENCES}

A.O.A.C. (1990). Official methods of analysis. association of official analytical chemists. In: K. Helrich, (Ed.) $15^{\text {th }}$ edition, Arlington, U.S.A.

Barot Amit, M, S. Pinto and H. Modha (2014). Development of technology for manufacture of bottle gourd ice cream. J. Nutr. Food Sci., 4: 316. doi: 10,4172/2155-9600, 1000316.

Burke, A. D. (1947)."Practical ice cream making". The Olson Publishing Co., Milwaukee, Wis., USA.

CoStat (1998). Users manual for CoStat version 6031. Cohort software, Berkeley; CA.

FAO LAB (1977). Laboratory manual. FAO Regional Dairy Development and Training Center for the Near East Laboratory Manual.

Herarld, T. J., F. M. Aramouni and M. H. Abu- Ghoush (2008). Comparison study of egg yolks and egg alternative in French Vanilla ice cream. J. Texture Stud., 39: 284-295.

Hoyer, C. (1997). European market trends in W. Buchheim (ed.), Session V: Market trends in ice cream, Proceedings of the international symposium pp.145-151. Athens, Greecer; International Dairy Federation.

Hussein, G. A. M. and I. E. Aumara (2006). Preparation and properties of probiotic frozen yoghurt made with sweet potato and pumpkin. Arab Univ. J. Agric. Sci., Ain Shams Univ., Cairo, 14: 679-695.

Karababa, E. and Y. Coskunder (2013). Physical properties of carob bean (Ceratonia Siliqua L.): An industrial gerrm yielding crop. Industrial Crops and Products, 42: 440-446.

Mahran, G. A., M. A. El-Ghandour, E. H. El-Bagoury, and A. F. Sayed (1984). Effect of skim milk powder storage on ice cream quality. Egyptian Journal of Dairy Science, 12: 267-273.

Marshall, R. T. and W. S. Arbuckle (1996). Ice cream. Fifth ed., Chapman and Hall, New York, USA.
Priolo, A., G. C. Wghom, M. Lanza, L. Biondi and P. Pennisi (2000). Polyethylene glycol as means for reducing the impact of condensed tannins in carob pulp: effects on lamb growth, performance and meat quality. J. Anim. Sci., 78: 810-816.

Salem, A. S. and M. I. Massoud (2003). Effect of using stevia (Stevia rebaudina Bertoni) leaves as natural non - caloric sweeteners on the physical chemical properties of fiber fotified frozen yoghurt. Egyptian J. Dairy Sci., 31: 61-70.

Santos, M., A. Rodrigues and J. A. Teixeria (2005). Production of dextran and fructose from carob pod extract and cheese whey by Leuconostoc mesenteroides. NRRL B512 (f). Biochemical Engineering Journal, 25: 1-6.

Tharp, B. W., B. Forrest, C. Swan, L. Dunning and M. Hilmore (1997). Basic factors affecting ice cream meltdown. In: Proceedings of the International Symposium of IDF. Athens. Greece, 18-19 September, pp. 54-64.

Yasin, N. M. N. and M. T. Ibrahim (2004). Antimicrobial antioxidative effects of carob powder and its effect on cake quality characteristics. Annals of agric. Sci., Moshtohor, 42: 1143-1158.

Youssef, M. K. E., H. M. Ali and M. M. El-Manfaloty (2013a). Nutritional assessment of wheat biscuits with carob pod powder (Ceratonia Siliqua L.). Food and Public Health, 3: 336-340.

Youssef, M. K. E., M. M. El-Manfaloty and H. M. Ali (2013b). Assessment of proximate chemical composition, nutritional status, fatty acid composition and phenolic compounds of carob (Ceratonia Siliqua L.). Food and Public Health, 3: 304-308.

Vani, B. and J. F. Zayas (1995). Wheat germ protein flour solubility and water retention. J. Food Sci., 60: $845-849$.

Winton, A. L. (1958). "Analysis of Foods". $3^{\text {rd }}$ printing, John Wiley and Sons Inc., New York. 6 pp.

\section{تأثير مسحوق قرون الخروب على الذواص الطبيعية و الحسية للمثلجات القثدية}

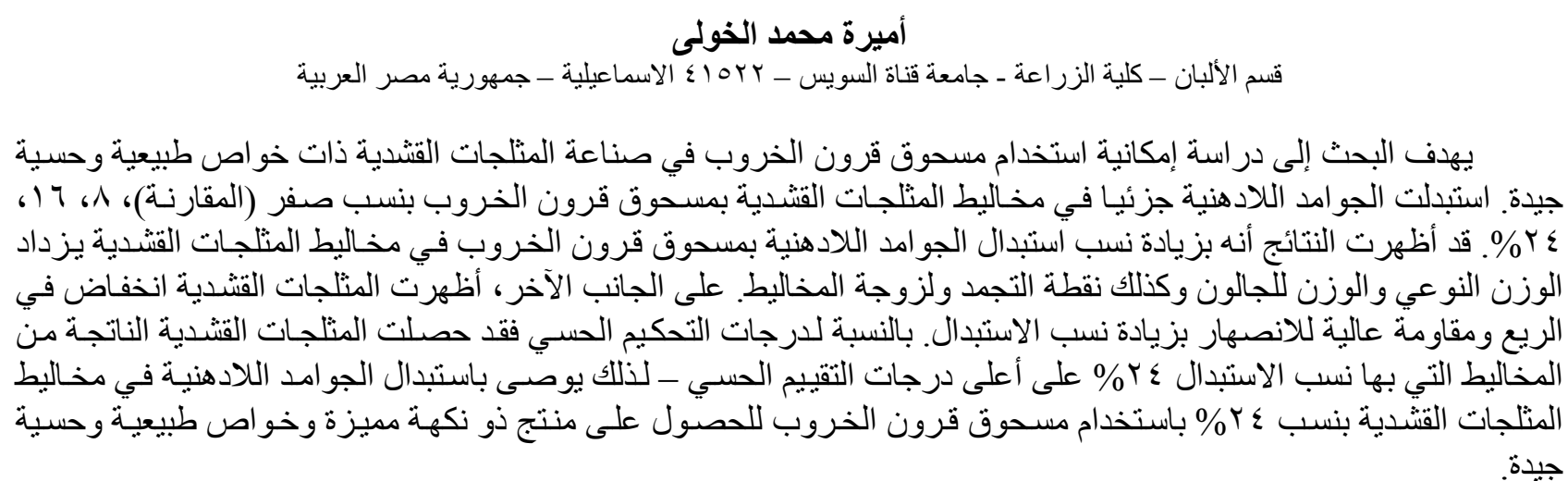

